\section{Torrid Panicgrass Dormancy Relief Through Exogenous Chemical Treatments and Seed Storage Optimization of Temperature and Relative Humidity Parameters}

\author{
Scott B. Lukas ${ }^{1,4}$, Joseph DeFrank ${ }^{2}$, Orville C. Baldos ${ }^{2}$, and \\ Ruijun Qin ${ }^{3}$
}

AdDitional Index words. germination, Hawaii, native, Panicum torridum, physiological dormancy, seed viability

SUMmARY. Seed dormancy is an evolutionary adaptation for increasing seedling survival by delaying germination and is found in many families of seed plants. Although dormancy is ecologically important, it becomes problematic during agronomic production and restoration. Torrid panicgrass (Panicum torridum) is a native Hawaiian annual grass that has been identified as a re-vegetation candidate for seasonally dry areas. Torrid panicgrass seed appears to possess a nondeep to intermediate physiological dormancy. This research aimed to characterize dormancy relief parameters by 1 ) evaluating exogenous hormonal, reactive oxygen intermediates, and simulated combustion product treatments; and 2) determining optimized storage conditions of relative humidity $(\mathrm{RH})$ and temperature over a 10 month duration. Results indicate that all exogenous chemical treatments tested were not effective at relieving the dormancy present in torrid panicgrass. Optimal storage conditions to relieve dormancy were found with seeds equilibrated to $12 \%$ $\mathrm{RH}$, stored at $30{ }^{\circ} \mathrm{C}$ for a period of 8 months resulting in $55 \%$ germination.

Maintenance of viability for long-term storage up to 10 months was best achieved with seeds stored at $12 \% \mathrm{RH}$ at 10,20 , or $30^{\circ} \mathrm{C}$.

S eed dormancy is an evolutionary adaptation for increasing seedling survival by delaying germination until conditions are favorable for seedling establishment (Fenner and Thompson, 2005). Although seed dormancy is ecologically important, it imposes hardships during agronomic production and restoration. Classification systems define five classes of seed dormancy: physiological dormancy (PD), morphological dormancy, morphophysiological dormancy (MPD), physical dormancy (PY), and combinational dormancy $(\mathrm{PY}+\mathrm{PD})$ (Baskin and Baskin,

Received for publication 13 Dec. 2018. Accepted for publication 20 Feb. 2019.

Published online 29 March 2019.

${ }^{1}$ Department of Horticulture, Oregon State University, Hermiston Agricultural Research and Extension Center, Hermiston, OR 97838

${ }^{2}$ Department of Tropical Plant and Soil Sciences, University of Hawaii at Manoa, Honolulu, HI 96822

${ }^{3}$ Department of Crop and Soil Science, Oregon State University, Hermiston Agricultural Research and Extension Center, Hermiston, OR 97838

${ }^{4}$ Corresponding author. E-mail: scott.lukas@oregonstate. edu.

This is an open access article distributed under the CC BY-NC-ND license (https://creativecommons.org/ licenses/by-nc-nd/4.0/).

https://doi.org/10.21273/HORTTECH04248-18
2004). Within the PD class, three levels can be defined as nondeep, intermediate, and deep, which can be partially elucidated by germination response to stimulatory chemicals (Baskin and Baskin, 2004). In many species, the depth of seed dormancy is controlled by the relationship between levels of gibberellic acid (GA) and abscisic acid (ABA) and is generally referred to as the hormonebalance theory (Wareing and Saunders, 1971). This theory proposes that as dormant seeds reach the optimum ratio of endogenous GA: $\mathrm{ABA}$, germination can proceed. This is the foundation for the widely accepted practice of treating dormant seeds with $\mathrm{GA}_{3}$, a well-established dormancy-breaking chemical (Kirmizi et al., 2010), and $\mathrm{GA}_{4+7}$, which is almost 1000 times more effective than $\mathrm{GA}_{3}$ (Hilhorst, 2011). Germination stimulation by GA is limited to the nondeep and intermediate levels of PD (Baskin and Baskin, 2004). Another method to induce germination involves the use of fluridone, which decreases the levels of endogenous ABA during early stages of imbibition (Grappin et al., 2000). Ethylene, which is also a hormonal treatment, has been recognized to relieve dormancy in seeds. It is produced in trace amounts by almost all higher plants and is involved in the control of growth and development processes that range from germination to senescence (Abeles et al., 2012). Exogenous ethylene stimulates the germination of dormant and nondormant seeds, although in some cases seed germination is unaffected by this hormone (Keçpczyński and Keçpczyńska, 1997). Ethephon, an ethylene-releasing compound, has been found to break dormancy more efficiently compared with ethylene (a gas at room temperatures). Aside from hormonal treatments, reactive oxygen donors such as sodium nitroprusside (SNP) and hydrogen peroxide can enhance germination or relieve dormancy in seeds (Beligni and Lamattina, 2000; Bethke et al., 201 1; Sarath and Mitchell, 2008). For species that are fire adapted, such as the native Hawaiian grass species tanglehead (Heteropogon contortus), simulated combustion products liquid smoke (a commercial food-grade flavoring) and cyanide can be effective germination promoters (Baldos, 2013).

Because seeds exhibiting intermediate or deep PD are not generally affected by stimulatory dormancy relief chemicals, it is necessary to understand optimum after-ripening storage conditions to maximize seed germination (Baskin and Baskin, 2004). Ultimate seed survival is

\begin{tabular}{llll}
\hline $\begin{array}{l}\text { Units } \\
\text { To convert U.S. to SI, } \\
\text { multiply by }\end{array}$ & U.S. unit & SI unit & $\begin{array}{l}\text { To convert SI to U.S., } \\
\text { multiply by }\end{array}$ \\
\hline 29.5735 & $\mathrm{fl} \mathrm{oz}$ & $\mathrm{mL}$ & 0.0338 \\
25.4 & inch $(\mathrm{es})$ & $\mathrm{mm}$ & 0.0394 \\
16.3871 & inch & $\mathrm{cm}^{3}$ & 0.0610 \\
28.3495 & $\mathrm{oz}$ & $\mathrm{g}$ & 0.0353 \\
28,350 & $\mathrm{oz}$ & $\mathrm{mg}$ & $3.5274 \times 10^{-5}$ \\
1 & $\mathrm{ppm}$ & $\mathrm{mg} \cdot \mathrm{L}^{-1}$ & 1 \\
$\left({ }^{\circ} \mathrm{F}-32\right) \div 1.8$ & ${ }^{\circ} \mathrm{F}$ & ${ }^{\circ} \mathrm{C}$ & $\left({ }^{\circ} \mathrm{C} \times 1.8\right)+32$ \\
$\left({ }^{\circ} \mathrm{F} \div 1.8\right)+255.37$ & ${ }^{\circ} \mathrm{F}$ & $\mathrm{K}$ & $(\mathrm{K}-255.37) \times 1.8$ \\
& & & \\
\end{tabular}


directly related to the time the seed has been exposed to unfavorable conditions of temperature or humidity (Barton, 1961). Numerous studies have used sealed chambers to evaluate the factors of temperature and $\mathrm{RH}$ to achieve dormancy relief (Baldos et al., 2014; Santhoshkumar and Veena, 2012). When using sealed desiccation chambers, specific levels of RH can be established and maintained using saturated salt solutions (Winston and Bates, 1960; Young, 1967), but proportions of water added to the salt (forming the saturated salt solution) to desiccate a given volume of water (contained in fresh seeds) are unclear.

Torrid panicgrass is a native Hawaiian annual grass that has been identified as a re-vegetation candidate for roadsides and conservation plantings in Hawaii. The intent of this study was to evaluate seed dormancy relief in torrid panicgrass through 1) exposure to the exogenous chemicals cyanide, ethanol, $\mathrm{GA}_{3}, \mathrm{GA}_{4+7}$, liquid smoke, hydrogen peroxide, fluridone, ethephon, and sodium nitroprusside; and 2) storage conditions equilibrated to three levels of $\mathrm{RH}$, stored at three temperatures over 10 months. The treatments of desiccation were chosen to resemble the natural ecological exposure of torrid panicgrass in the wild. Before the dormancy relief storage study, a calibration procedure was used to determine the components of the saturated salt lithium chloride $(\mathrm{LiCl})$ solution that could absorb moisture released by seeds in a sealed vessel while lowering and maintaining the target $\mathrm{RH}$ level.

\section{Materials and methods}

Plant seed material. Two separate batches of torrid panicgrass seeds were used throughout these experiments to determine the consistency of the treatment response in replicated trials. Both seed batches were harvested from wild populations found on the Hawaiian island of Molokai and stored in sealed bags in a $10{ }^{\circ} \mathrm{C}$ refrigerator until use. Seed batch 1 (SBl) was harvested in May 2013. Seed batch 2 (SB2) was harvested in May 2014. Before experimental use, seeds were air dried and stored in sealed containers at $5{ }^{\circ} \mathrm{C}$. Both seed batches showed higher than $90 \%$ seed viability before experimental evaluation using a $1 \%$ tetrazolium chloride (TZ) solution following standardized methods outlined by the International Seed Testing Association (1996).

Germination parameters. For all germination studies, experimental units consisted of 50 seeds exposed to the experimental treatment/ treatment combinations with four replications, repeated for each seed batch. Each experimental unit was incubated in $90-\mathrm{mm}$ petri dishes premoistened with $3 \mathrm{~mL}$ distilled water and lined with filter paper (Whatman \#2; GE Healthcare, Little Chalfont, UK). Petri dishes were placed in an alternating temperature germination chamber with four T5 high output 24-W 6400-K bulbs (AgroBrite; Hydrofarm, Petaluma, CA) for $14 \mathrm{~h}$ of light at $28{ }^{\circ} \mathrm{C}$ and $10 \mathrm{~h}$ of dark at $24{ }^{\circ} \mathrm{C}$. Experimental conditions during the seed germination period were monitored and recorded with a data logger (Hobo UX100; Onset Computer Corp., Bourne, MA); $1.5 \mathrm{~mL}$ of distilled water was added to petri dishes as the perimeter of the filter paper began to appear dry over the 14-d germination period. Germination was recorded when the seed radicle protruded $1 \mathrm{~mm}$ from the seed testa. Seed viability testing was not conducted on the remaining seeds that did not germinate after the 14-d period.

WATER IMbIBITION OF SEED. To help classify dormancy type, it was necessary to determine if the seed testa was permitting water to pass through to the seed endosperm. Although it is well established that seedcoats of grasses are water permeable, this study attempted to provide a framework of methods for evaluating dormancy. This study evaluated the ability of after-ripened germinable torrid panicgrass seeds to imbibe water compared with freshly harvested nongerminable seeds. When fresh seeds are able to imbibe water and not germinate, it is unlikely that a physical dormancy mechanism is prohibiting germination. Weight increases were measured in 100 seed units over a 24 -h period exposed to distilled water on filter paper, with three replications. Weight measurements were taken before exposure to water, and after exposure at 1, 2, 4, 12 , and $24 \mathrm{~h}$. At each interval, seeds were removed from the saturated filter paper, blotted dry, weighed, and returned to the filter paper
(Baskin et al., 2004). Weight was measured using an analytical balance with a weight sensitivity range of 0.1 $\mathrm{mg}$. The amount of water taken up was determined by actual weight increases and converted to the percentage weight increase:

$$
W i=\frac{(W i-W d)}{W d} \times 100,
$$

where $W i$ and $W d$ are weight of imbibed and dry seeds, respectively.

A random sample of the germinable seed batch used for the imbibition study had a $55 \%$ germination at the start of the experiment, with high viability $(90 \%)$. The freshly harvested seed was of high viability $(96 \%)$ but fully dormant with no germination. Data expressed as percent seed moisture increase was compared between germinable torrid panicgrass seed and freshly harvested seed over imbibition exposure times. Data were analyzed for weight increases as a split-plot with seed batch (i.e., germinable and fresh) as the main effect and imbibition time as the split-plot effect, in the statistical software program Statistix (version 10.0; Analytical Software, Tallahassee, FL).

DORMANCY RELIEF THROUgH EXogenous CHEMiCALS. After determining that freshly harvested seed could not germinate, seed response to known germination stimulators was determined to characterize the physiological nature of torrid panicgrass dormancy. Torrid panicgrass seeds were exposed to treatments of cyanide, ethanol, $\mathrm{GA}_{3}, \mathrm{GA}_{4+7}$, liquid smoke, hydrogen peroxide, fluridone, ethephon, and sodium nitroprusside individually to determine their effect on dormancy relief (Table 1). Exposure was achieved by making solutions of the desired chemicals with distilled water, then applying aliquots directly to the petri dish with the dormant seeds. Germination responses of zero to less than $4 \%$ were excluded from the analysis due to their impact on the magnitude of mean square error and the potential to magnify treatment effects (Reeve and Strom, 2004). Data were analyzed as a random complete block design using standard least squares fit model in the statistical program JMP Pro (version 11; SAS Institute, Cary, NC).

DESICCATION CHAMBER CALIBRATION. Twenty grams of $\mathrm{LiCl}$ salt was mixed with $0,3.0,6.0,12.0$ and $24.0 \mathrm{~mL}$ of distilled water. These 
Table 1. List of exogenous chemicals, rates, and respective citations tested to relieve dormancy in torrid panicgrass seeds. Exposure was achieved by making solutions of the desired chemicals with distilled water, then applying aliquots directly to the petri dish with the dormant seeds.

\begin{tabular}{|c|c|c|}
\hline Treatment & Rate $^{\mathrm{z}}$ & Citation \\
\hline Ethanol & $0.3 \mathrm{M}$ & Tischler and Young (1983) \\
\hline Hydrogen peroxide & $20 \mathrm{~mm}$ & Sarath and Mitchell (2008) \\
\hline \multirow[t]{2}{*}{ Gibberellic acid (GA) $\mathrm{GA}_{3}$} & $100 \mathrm{ppm}$ & Kirmizi et al. (2010) \\
\hline & $200 \mathrm{ppm}$ & \\
\hline \multirow[t]{5}{*}{$\mathrm{GA}_{4+7}$} & $50 \mu \mathrm{M}$ & Hilhorst (2011) \\
\hline & $100 \mu \mathrm{M}$ & \\
\hline & $200 \mu \mathrm{M}$ & \\
\hline & $400 \mu \mathrm{M}$ & \\
\hline & $800 \mu \mathrm{M}$ & \\
\hline Liquid smoke & $1 \%$ & Baldos (2013) \\
\hline Potassium cyanide & $0.5 \mathrm{~mm}$ & Bethke et al. (2011) \\
\hline \multirow[t]{4}{*}{ Fluridone } & $10 \mu \mathrm{M}$ & Grappin et al. (2000) \\
\hline & $20 \mu_{\mathrm{M}}$ & \\
\hline & $40 \mu \mathrm{M}$ & \\
\hline & $80 \mu \mathrm{M}$ & \\
\hline \multirow[t]{4}{*}{ Ethephon } & $0.5 \mathrm{~mm}$ & Keçpczyński and Keçpczyńska (1997) \\
\hline & $1.0 \mathrm{~mm}$ & \\
\hline & $2.0 \mathrm{~mm}$ & \\
\hline & $4.0 \mathrm{~mm}$ & \\
\hline \multirow[t]{4}{*}{ Sodium nitroprusside (SNP) } & $50 \mu \mathrm{M}$ & Bethke et al. (2011) \\
\hline & $100 \mu \mathrm{M}$ & \\
\hline & $150 \mu \mathrm{M}$ & \\
\hline & $200 \mu \mathrm{M}$ & \\
\hline Distilled water & - & \\
\hline
\end{tabular}

${ }^{\mathrm{z}} 1 \mathrm{ppm}=1 \mathrm{mg} \cdot \mathrm{L}^{-1}$.

water/salt mixtures were placed in a sealed desiccation chamber that contained $5 \mathrm{~mL}$ of water in a separate container. The drop in $\mathrm{RH}$ was recorded inside the chamber for 18 $\mathrm{d}$ with a data logger (Hobo UXI00) to determine the optimal composition of saturated salt solutions (the proportions of salt and water) and the moisture levels within the desiccation chambers that could be absorbed but still reduce and maintain the reported level of RH.

DORMANCY RELIEF AND VIABILITY MAINTENANCE THROUGH STORAGE CONDITIONS. Seed after-ripening conditions were evaluated for the parameters of temperature and $\mathrm{RH}$ for both seed batches. Three RH levels were imposed on seeds placed into unsealed 1.5-mL microcentrifuge tubes with $\mathrm{O}$ ring gasket lids (Fisherbrand; Fisher Scientific, Pittsburgh, PA) and placed in sealed nonvacuum desiccation chambers (Bel-Art; Scienceware, Wayne, NJ). Humidity levels were maintained using saturated salt solutions of $\mathrm{LiCl}$ $(12 \% \mathrm{RH})$, calcium nitrate $(50 \% \mathrm{RH})$, and sodium chloride (75\% RH) (Winston and Bates, 1960; Young, 1967). Each desiccation chamber contained a petri dish with $20 \mathrm{~g}$ of salt mixed with $6 \mathrm{~mL}$ of distilled water to reduce and maintain specific levels of RH based on the type of salt used. After $30 \mathrm{~d}$ in the sealed desiccator, seed-filled tubes were immediately sealed and transferred to three incubation temperature $\left(10,20\right.$, and $\left.30^{\circ} \mathrm{C}\right)$ chambers. Seeds were withdrawn from the temperature chambers at $0,2,4,6,8$, and 10 months to test for germination, seed viability (TZ), and moisture content. Throughout the experiment, temperature and humidity levels within the chambers were monitored in real time and logged electronically with data loggers (Hobo UXI00).

Germination data were analyzed as a split-split-split-split-plot, classifying seed batch at the main-plot effect, $\mathrm{RH}$ as sub-plot effect, temperature as sub-sub-plot effect and duration in storage as sub-sub-sub-plot effect in the statistical software program Statistix 10.0. Due to inconsistent germination found in month 0 in $S B 1$, and no germination in SB2, data for month 0 was removed from the analysis. The remaining analysis for germination data was conducted over the three factors at durations of $2,4,6,8$, and 10 months. The analysis for seed viability was conducted with the same data analysis format as germination, but all months of storage were included in the analysis.

\section{Results}

WATER IMBIBITION OF SEEDS. No significant interactions were present between the factors of seed batch $x$ imbibition time on seed weight increases, thus treatment means were pooled over seed batch $(P=0.057)$. The results indicated a significant weight increase over the 24 -h imbibition period $(P<0.001)$. Both germinable seeds and freshly harvested seeds were similar in their ability to imbibe water, with both seed batches showing a $15.3 \%$ final seed weight increase. Imbibition weights significantly increased within the first $4 \mathrm{~h}$ of incubation and leveled off thereafter (Table 2). This result indicates that the torrid panicgrass seed testa is not limiting the uptake of water into the endosperm, an indication that dormancy is not physically based [PY (Baskin et al., 2004)].

DORMANCY RELIEF THROUGH EXOGENOUS CHEMICALS. Torrid panicgrass seeds were not stimulated by any of the exogenous chemicals tested. All treatments and rates resulted in zero germination, despite seeds exhibiting viability. The lack of response may indicate that the dormancy present is a nondeep to intermediate form of PD (Baldos et al., 2015; Baskin and Baskin, 2004).

DESICCATION CHAMBER CALIBRATION. Calibration of saturated salt solutions indicated that $20 \mathrm{~g}$ of $\mathrm{LiCl}$ combined with $6 \mathrm{~mL}$ of distilled water reduced ambient humidity levels $(50 \%)$ to target $12.5 \% \mathrm{RH}$ within $6 \mathrm{~d}$ in a $1700-\mathrm{cm}^{3}$ chamber in the presence of $5 \mathrm{~mL}$ of distilled water. The $12.5 \%$ target $\mathrm{RH}$ was not achieved with the other volumes of water added to the $20 \mathrm{~g}$ of $\mathrm{LiCl}$ (Table 3). These results confirm the effectiveness of the salt and water mixture to remove the required amount of moisture in torrid panicgrass seeds during dry seed storage to provide dormancy relief and viability maintenance. The other salts used in this research (calcium nitrate and sodium chloride) are required to absorb less moisture (to impose higher $\mathrm{RH}$ levels of $50 \%$ and $75 \%$ ) from the chambers, therefore the water volumes to produce 
Table 2. Torrid panicgrass seed percent weight increase over a $24-h$ distilled water imbibition period. No interactions between the effects of fresh or germinable seed were detected, thus combined results are presented.

\begin{tabular}{lc}
\hline Time (h) & Wt increase (\%) \\
\hline 0 & $0.00 \mathrm{c}^{\mathrm{z}}$ \\
1 & $5.21 \mathrm{~b}$ \\
2 & $8.14 \mathrm{~b}$ \\
4 & $15.64 \mathrm{a}$ \\
12 & $14.66 \mathrm{a}$ \\
24 & $15.31 \mathrm{a}$ \\
\hline
\end{tabular}

${ }^{\mathrm{z}}$ Means are separated using Tukey's honestly significant difference comparison at $P=0.05$. Means within columns followed by the same letter are not significantly different.

their saturated salt solutions were based on the $\mathrm{LiCl}$ calibration.

DORMANCY RELIEF THROUGH STORAGE CONDITIONS. The highest level significant interaction was found among the three factors of temperature $\times \mathrm{RH} \times$ months in storage $(P<$ 0.001 ), allowing for means to be pooled across seed batches. The highest level of germination was recorded when storage conditions of $12 \%$ humidity at $30{ }^{\circ} \mathrm{C}$ were imposed on dormant seeds (Fig. 1). Under these conditions, germination increased steadily up to $55 \%$ at 8 months in storage and then dropped slightly to $49 \%$ at 10 months (Table 4 ). Storage at $20{ }^{\circ} \mathrm{C}(12 \% \mathrm{RH})$ also showed similar but consistently lower levels of germination enhancement that peaked at 6 months at $20 \%$ and did not significantly change with an additional 4 months of storage. Storage at $10{ }^{\circ} \mathrm{C}(12 \% \mathrm{RH})$ resulted in minimal germination, peaking at less than $10 \%$ germination with 8 months of storage. At $75 \%$ humidity, there was minor stimulation in germination with storage. The germination response at $50 \% \mathrm{RH}$ was similar to that at $75 \%$ with only slight enhancement during the storage duration when the $30{ }^{\circ} \mathrm{C}$ temperature was imposed on dormant seeds.

VIABILITY MAINTENANCE THROUGH STORAGE CONDITIONS. A significant four-way interaction was identified for the factors of seed batch $\times$ temperature $\times \mathrm{RH} \times$ months in storage $(P<0.001)$, thus factors of temperature, $\mathrm{RH}$, and storage duration were presented separately for both seed batches. The general trend between both seed batches was that at

Table 3. Desiccation chamber relative humidity $(\mathrm{RH})$ calibration using saturated lithium chloride. The optimal RH level of $12.5 \%$ was obtained by adding $6 \mathrm{~mL}$ distilled water to $20 \mathrm{~g}(0.7 \mathrm{oz})$ lithium chloride in a $1700-\mathrm{cm}^{3}\left(103.7-\mathrm{inch}^{3}\right)$ desiccation chamber.

\begin{tabular}{lcc}
\hline Water added $(\mathrm{mL})^{\mathbf{z}}$ & RH level achieved (\%) & Time to RH equilibration $(\mathrm{d})$ \\
\hline 0 & 13.0 & 6 \\
3 & 13.0 & 6 \\
6 & 12.5 & 6 \\
12 & 13.5 & 5 \\
24 & 26.0 & 4 \\
\hline
\end{tabular}

${ }^{\mathrm{z}} 1 \mathrm{~mL}=0.0338 \mathrm{fl} \mathrm{oz}$.

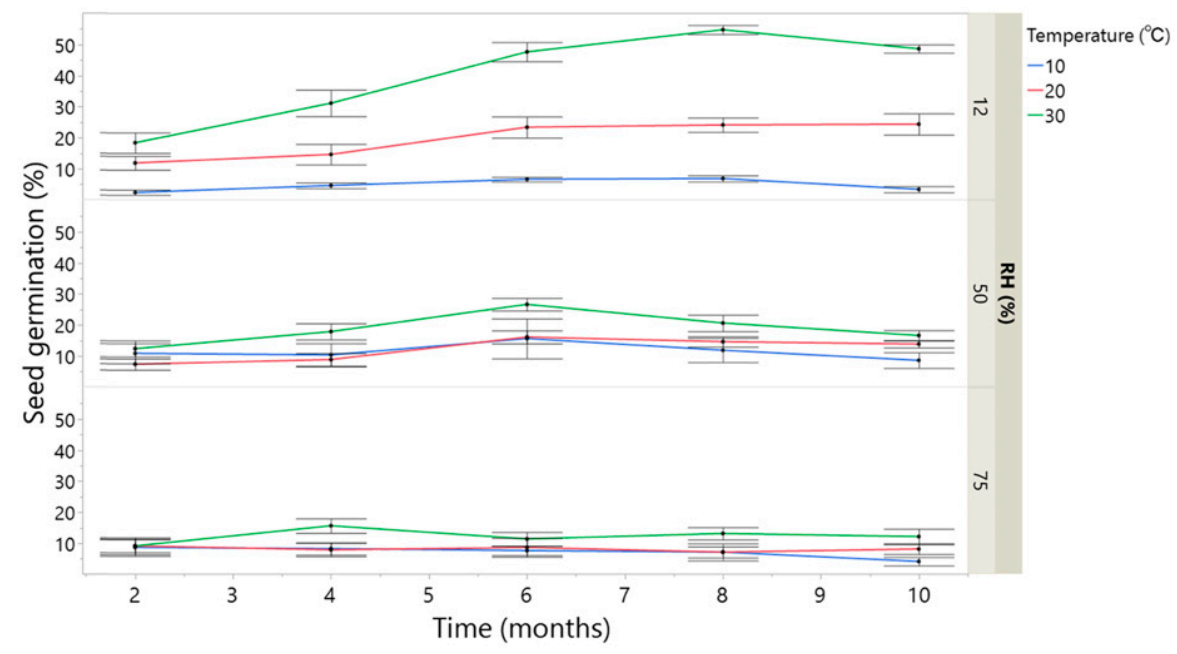

Fig. 1. Seed dormancy relief through germination of torrid panicgrass exposed to varying levels of relative humidity $(\mathrm{RH})$ and temperature over a 10 -month storage duration. Data are pooled over two seed batches and presented with SE bars; $1.8 \times{ }^{\circ} \mathrm{C}+32={ }^{\circ} \mathrm{F}$.

Table 4. Torrid panicgrass percent germination means representing dormancy relief based on varying levels of relative humidity $(\mathrm{RH})$ and temperature over a 10-month storage duration. Shading over values indicates the optimal treatments.

\begin{tabular}{|c|c|c|c|c|c|c|}
\hline \multirow[b]{3}{*}{ Storage temp $\left({ }^{\circ} \mathbf{C}\right)^{\mathrm{z}}$} & \multirow[b]{3}{*}{ RH (\%) } & \multicolumn{5}{|c|}{ Seed germination (\%) } \\
\hline & & \multicolumn{5}{|c|}{ Time in storage (mo.) } \\
\hline & & 2 & 4 & 6 & 8 & 10 \\
\hline \multirow[t]{3}{*}{10} & 12 & $3 v^{y}$ & $5 \mathrm{~s}-\mathrm{V}$ & $7 \mathrm{r}-\mathrm{v}$ & $7 \mathrm{r}-\mathrm{u}$ & $4 \mathrm{uv}$ \\
\hline & 50 & $111-r$ & $111-r$ & $16 \mathrm{~g}-\mathrm{k}$ & $12 j-p$ & $9 n-s$ \\
\hline & 75 & $9 n-s$ & $8 n-t$ & $8 \mathrm{p}-\mathrm{u}$ & $7 \mathrm{q}-\mathrm{u}$ & $4 \mathrm{t}-\mathrm{v}$ \\
\hline \multirow[t]{3}{*}{20} & 12 & $12 j-p$ & $15 \mathrm{j}-1$ & $24 \mathrm{de}$ & $24 \mathrm{de}$ & $25 \mathrm{de}$ \\
\hline & 50 & $8 \mathrm{q}-\mathrm{u}$ & $9 \mathrm{~m}-\mathrm{s}$ & $16 \mathrm{~g}-\mathrm{j}$ & $15 \mathrm{~g}-1$ & $14 \mathrm{~h}-1$ \\
\hline & 75 & $9 \mathrm{~m}-\mathrm{r}$ & $80-t$ & $9 \mathrm{n}-\mathrm{s}$ & $7 q-u$ & $8 n-t$ \\
\hline \multirow[t]{3}{*}{30} & 12 & $19 \mathrm{fg}$ & $31 \mathrm{c}$ & $48 \mathrm{~b}$ & $55 \mathrm{a}$ & $49 \mathrm{~b}$ \\
\hline & 50 & $13 \mathrm{i}-\mathrm{n}$ & $18 \mathrm{f}-\mathrm{h}$ & $27 \mathrm{~d}$ & $21 \mathrm{ef}$ & $17 \mathrm{f}-\mathrm{i}$ \\
\hline & 75 & $9 \mathrm{~m}-\mathrm{r}$ & $16 \mathrm{~g}-\mathrm{k}$ & $12 \mathrm{k}-\mathrm{q}$ & $13 \mathrm{i}-\mathrm{m}$ & $12 \mathrm{j}-\mathrm{O}$ \\
\hline
\end{tabular}

\section{${ }^{\mathrm{z}} 1.8 \times{ }^{\circ} \mathrm{C}+32={ }^{\circ} \mathrm{F}$}

${ }^{\mathrm{y}}$ Means are separated using Tukey's honestly significant difference comparison at $P=0.05$. Means within columns and rows followed by the same letter are not significantly different. Data are pooled over two seed batches.

the lowest RH level (12\%), viability loss was minimized over the 10month duration. As RH level was raised to $50 \%$ and $75 \%$, increasing losses of viability were detected over the storage duration, with the lowest seed viability at $75 \% \mathrm{RH}$. Within the $12 \% \mathrm{RH}$ level, temperature increases produced a slight decline in viability. The $50 \% \mathrm{RH}$ level exhibited a more defined loss of viability as temperatures increased over time. Within the 
75\% RH treatments, increased temperatures produced the most distinct and reduced losses of viability, with the greatest viability losses found with the highest temperature of $30{ }^{\circ} \mathrm{C}$ (Fig. 2). In SB2, the magnitude of viability loss was greater than $S B I$ and most obvious at the highest $\mathrm{RH}$ $(75 \%)$ and the warmest temperature $\left(30^{\circ} \mathrm{C}\right)$ over 10 months. Torrid panicgrass seed viability was maintained at the highest levels at $12 \% \mathrm{RH}$ during the 10 months of storage within the temperature range of 10 to $30{ }^{\circ} \mathrm{C}$. $\mathrm{RH}$ levels above $12 \%$ reduced seed viability and are not recommended during storage.

\section{Discussion}

There was no restriction of water uptake through seed testa to the endosperm, reinforcing the hypothesis that the dormancy present is not physically based. Following the logical progression of treatments to relieve dormancy led to the evaluation of PD with exogenous chemical treatments (Baskin and Baskin, 2004). As noted in the results, no germination stimulation was detected in response to any of the chemicals evaluated. It is well established that different plant species frequently exhibit significant variations in their germination responses to exogenously imposed chemical stimulants (Bewley, 1997).

Differences detected between the storage response of $\mathrm{SBl}$ and $\mathrm{SB} 2$ at the initiation (month 0 ) could be attributed to the duration that SBI was stored before use in the experiment. $\mathrm{SBl}$ was stored in a $10^{\circ} \mathrm{C}$ refrigerator for 4 months before evaluation of storage variables on dormancy relief, compared with SB2, which was used 2 weeks after harvest. Ideally, studies on factors impacting seed dormancy relief should be conducted on seeds collected from the field as soon after harvest as possible. The wild stands of torrid panicgrass that were the source of seeds for these studies were located in remote areas of Molokai, extending the time between seed collection and the initiation of experiments. It has also been reported that the depth of dormancy can be affected by time of year harvesting of tanglehead seeds (Baldos et al., 2014). Both torrid panicgrass seed batches used in this research were harvested in May but were separated by 1 year, thus the unrecorded environmental conditions at the collection sites could account for differences in the observed depth of dormancy (Andersson and Milberg, 1998).

When using saturated salts for humidity regulation, it is recommended that salt and water proportions are calibrated for their impact within the chambers used for controlled seed desiccation. This research supports the addition of $6 \mathrm{~mL}$ distilled water to $20 \mathrm{~g}$ of $\mathrm{LiCl}$ to provide the reduction and maintenance of the target $12 \% \mathrm{RH}$ for $11 \mathrm{~g}$ of torrid panicgrass seed in a $1700-\mathrm{cm}^{3}$ desiccator. Calibration methods discussed in this paper can be up-scaled for seed desiccation in a larger-capacity chamber, provided that the entire volume of seed can be uniformly exposed to the desired level of $\mathrm{RH}$. A practitioner can calculate the amount of saturated salts needed to desiccate greater amounts of seed within an airtight commercially available vessel, such as a sealable plastic bucket or insulated beverage cooler.

Seed viability of torrid panicgrass remained stable over the duration of the experiment when equilibrated to $12 \% \mathrm{RH}$; however, as RH increased $(50 \%$ and $75 \%)$, seed viability decreased. Ultimate seed survival is

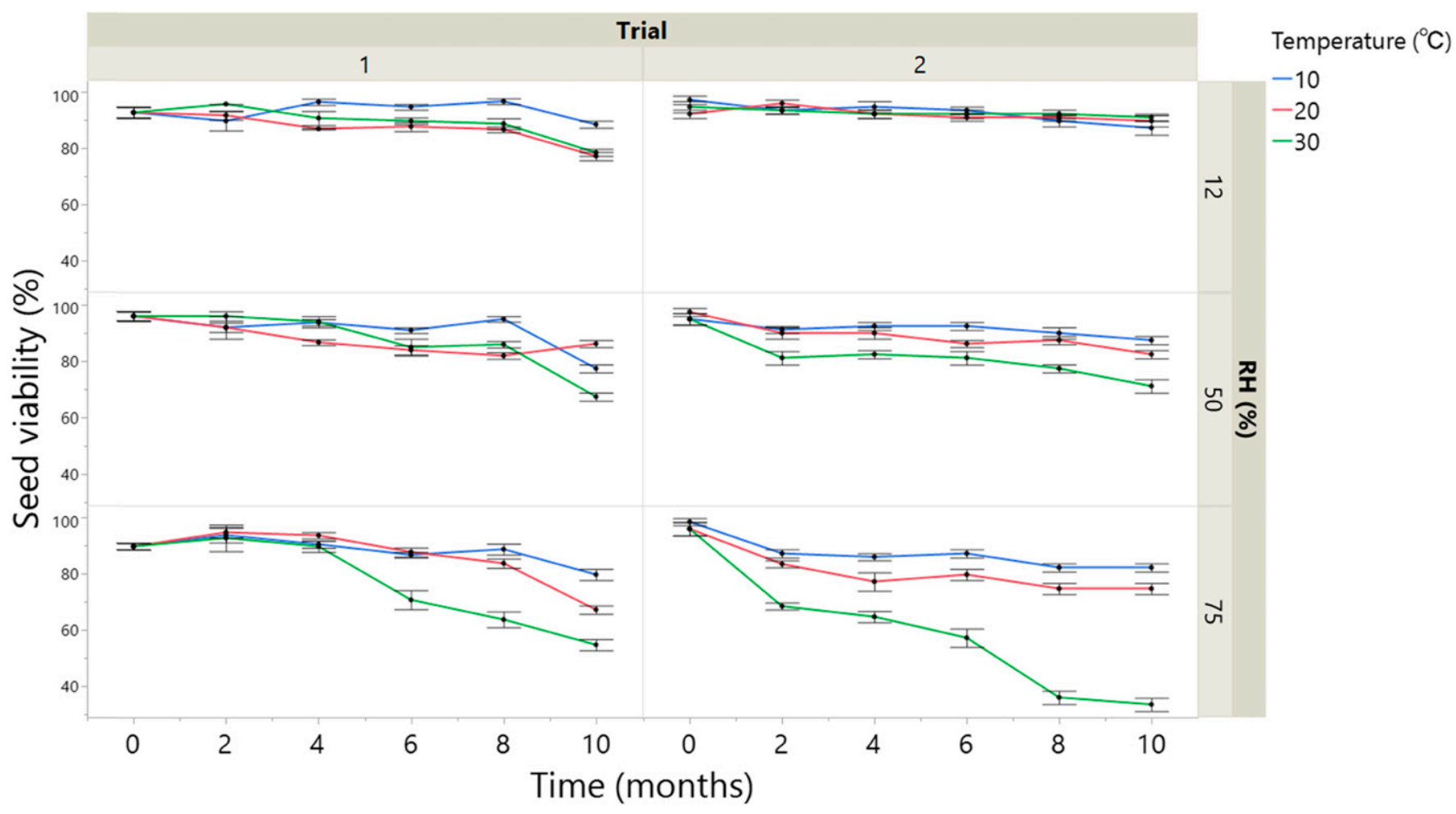

Fig. 2. Seed viability maintenance of torrid panicgrass seeds exposed to varying levels of relative humidity (RH) and temperature over a 10-month storage duration. Data are represented over two seed batches and plotted with SE bars; $1.8 \times{ }^{\circ} \mathrm{C}+32={ }^{\circ} \mathrm{F}$. 
directly related to the time the seed has been exposed to unfavorable conditions of temperature or humidity (Barton, 1961; Harrington, 1972; Roberts, 1972). Storage parameters can greatly impact seeds both in terms of relief of dormancy and persistence over time (Priestley, 1986).

In summary, exogenous chemical treatments did not relieve torrid panicgrass dormancy; however, seed germination was elevated from $0 \%$ to $4 \%$ to a maximum of $55 \%$ germination by storage maintained at $12 \% \mathrm{RH}$ at $30{ }^{\circ} \mathrm{C}$ for a duration of 8 months. Torrid panicgrass seeds can maintain viability for up to 10 months when a storage $\mathrm{RH}$ of $12 \%$ is imposed and consistently maintained.

\section{Literature cited}

Abeles, F.B., P.W. Morgan, and M.E. Saltveit, Jr. 2012. Ethylene in plant biology. 2nd ed. Academic Press, San Diego, CA.

Andersson, L. and P. Milberg. 1998. Variation in seed dormancy among mother plants, populations and years of seed collection. Seed Sci. Res. 8:29-38.

Baldos, O.C. 2013. Seed dormancy, smoke-stimulated germination and harvest timing of pili grass (Heterpogon contortus), a native Hawaiian grass with potential for expanded re-vegetation use. Univ. Hawaii at Manoa, Honolulu, PhD Diss. 3585985.

Baldos, O.C., J. DeFrank, M. Kramer, and G.S. Sakamoto. 2014. Storage humidity and temperature affect dormancy loss and viability of tanglehead (Heteropogon contortus) seeds. HortScience 49: 1328-1334.

Baldos, O.C., J. DeFrank, and G.S. Sakamoto. 2015. Germination response of dormant tanglehead (Heteropogon contortus) seeds to smoke-infused water and the smoke-associated stimulatory compounds, karrikinolide and cyanide. HortScience 50:421-429.

Barton, L.V. 1961. Seed preservation and longevity. Leonard Hill, New York, NY.

Baskin, J.M. and C.C. Baskin. 2004. A classification system for seed dormancy. Seed Sci. Res. 14:1-16.

Baskin, J.M., B.H. Davis, C.C. Baskin, S. M. Gleason, and S. Cordell. 2004. Physical dormancy in seeds of Dodonaea viscosa (Sapindales, Sapindaceae) from Hawaii. Seed Sci. Res. 14:81-90.

Beligni, M.V. and L. Lamattina. 2000. Nitric oxide stimulates seed germination and de-etiolation, and inhibits hypocotyl elongation, three light-inducible responses in plants. Planta 210:215-221.

Bethke, P., I.L. Libourel, J. Vitecek, and R. Jones. 2011. Nitric oxide methods in seed biology, p. 385-400. In: A. Kermode (ed.). Seed dormancy. Humana Press, New York, NY.

Bewley, J.D. 1997. Seed germination and dormancy. Plant Cell 9:1055-1066.

Fenner, M. and K. Thompson. 2005. The ecology of seeds. Oxford Univ. Press, Oxford, UK.

Grappin, P., D. Bouinot, B. Sotta, E. Miginiac, and M. Jullien. 2000. Control of seed dormancy in Nicotiana plumbaginifolia: Post-imbibition abscisic acid synthesis imposes dormancy maintenance. Planta 210:279-285.

Harrington, J.F. 1972. Seed storage and longevity. Seed Biol. 3:145-245.

Hilhorst, H.M. 2011. Standardizing seed dormancy research, p. 43-52. In: A. Kermode (ed.). Seed dormancy. Humana Press, New York, NY.

International Seed Testing Association. 1996. International rules for seed testing. Seed Sci. Technol. Rules 1996. Intl. Seed Testing Assn., Zurich, Switzerland.

Keçpczyński, J. and E. Keçpczyńska. 1997. Ethylene in seed dormancy and germination. Physiol. Plant. 101:720726.

Kirmizi, S., G. Guleryuz, H. Arslan, and F.S. Sakar. 2010. Effects of moist chilling, gibberellic acid, and scarification on seed dormancy in the rare endemic Pedicularis olympica (Scrophulariaceae). Turk. J. Bot. 34:225-232.

Priestley, D.A. 1986. Seed aging: Implications for seed storage and persistence in the soil. Comstock Assoc., Eugene, OR.

Reeve, J.D. and B.L. Strom. 2004. Statistical problems encountered in trapping studies of scolytids and associated insects. J. Chem. Ecol. 30:1575-1590.

Roberts, E.H. 1972. Storage environment and the control of viability, p. 1458. In: E.H. Roberts (ed.). Viability of seeds. Cambridge Univ. Press, Cambridge, UK.

Santhoshkumar, G. and G. Veena. 2012. Effect of temperature and relative humidity on seed viability and storage of senna (Cassia angustifolia) seeds. Intl. J. Plant Sci. 7:117-121.

Sarath, G. and R.B. Mitchell. 2008. Aged switchgrass seed lot's response to dormancy-breaking chemicals. Seed Technol. 30:7-16.

Tischler, C.R. and B.A. Young. 1983. Effects of chemical and physical treatments on germination of freshly-harvested kleingrass seed. Crop Sci. 23:789-792.

Wareing, P. and P. Saunders. 1971. Hormones and dormancy. Annu. Rev. Plant Physiol. 22:261-288.

Winston, P.W. and D.H. Bates. 1960. Saturated solutions for the control of humidity in biological research. Ecology 41:232-237.

Young, J.F. 1967. Humidity control in the laboratory using salt solutions - A review. J. Appl. Chem. (Lond.) 17:241245. 